\title{
De la Historia a los relatos. El patrimonio cultural como herramienta de comunicación abierta, participación ciudadana y desarrollo urbano
}

\author{
Luis D. Rivero Moreno | Project Manager, TASO desarrollos S. L. \\ URL de la contribución <http://www.iaph.es/revistaph/index.php/revistaph/article/view/4384>
}

En un mundo mayoritariamente urbano, la necesidad de mejorar las condiciones de vida en las ciudades se ha convertido en un debate prioritario a nivel global. Las ciudades comparten redes (SASSEN, 2016), retos y problemas en todas las latitudes casi sin variación: contaminación, movilidad, sostenibilidad... Por eso el establecimiento de unas directrices internacionales parece ser un buen camino para diseñar espacios y métodos de reflexión sobre lo que debe ser el futuro de las ciudades.

Sin embargo, tal y como se puede apreciar en el caso de las agendas urbanas: la disposición de establecer parámetros que sinteticen y engloben una tendencia internacional y sean válidos en muy diversas situaciones y ámbitos tiene importantes desventajas. Las conceptualizaciones terminan por ser excesivamente generales $\mathrm{y}$, si bien llenas de buenas intenciones, alcanzan una escasa capacidad como herramientas prácticas. Además su impacto real en la ciudadanía es escaso, si no nulo, pues directamente estas agendas son inaccesibles para el gran público.

Paradójicamente, existe una corriente generalizada que lleva a señalar la necesidad de una perspectiva de base (en inglés grassroots o bottom-up) en el desarrollo urbano y la gestión cultural. Palabras de moda que se considera imprescindible anotar desde un punto de vista político y académico. No obstante, el supuesto acercamiento a la participación de amplias capas sociales se ve rápidamente en contradicción con la propia metodología y estructura empleada en la elaboración de este tipo de documentos.

En todo este contexto, el patrimonio cultural aparece como un ámbito de impacto creciente a nivel político, social y económico en el desarrollo de urbano. Su capacidad ha sido tradicionalmente infravalorada. La celebración del Año Europeo del Patrimonio Cultural durante 2018 es un indicador claro de esta tendencia a nivel continental. El patrimonio ha dejado de ser visto tan sólo como una herramienta de atracción de visitantes unido al turismo de masas, mecanismo fundamental de la industria cultural desatada desde la segunda mitad del siglo XX.

En las últimas décadas se ha producido un enorme ensanchamiento de sus límites como concepto, un hecho que ha conducido a la apertura de nuevas posibilidades en su utilidad práctica. Actualmente no es considerado como un modo de conocimiento y conservación de los vestigios del pasado, sino una herramienta viva de creación de redes de cohesión social, identidad y memoria, un método de comunicación que puede ayudar a mejorar la calidad de vida de las personas. Por ello, en el ámbito del desarrollo urbano ha visto incrementado su radio de acción. El patrimonio es, a día de hoy, el fundamento sobre el que se sustenta la construcción de la ciudad del futuro.

Esta tendencia debe ser aprovechada para sacar el máximo partido a la capacidad demostrada por el propio patrimonio a lo largo de la historia: su propia resiliencia y resistencia al paso del tiempo, y su capacidad de activación de la memoria y los espacios comunes pueden ejercer de referente clave respecto a los objetivos expuestos en las agendas urbanas. El patrimonio marca en las últimas décadas una senda clara hacia la participación ciudadana, la apertura de las estructuras institucionales a la comunidad y la inclusión de todos los ciudadanos en las mismas, sea cual sea su condición y origen. Existen 
a debate El papel del patrimonio en las nuevas políticas para la cultura, la ciudad y el territorio: las agendas urbanas como marco de oportunidad

| coordinan Blanca del Espino Hidalgo, Rafael Merinero Rodríguez

centenares de proyectos que demuestran este hecho en todas las latitudes.

Por ello el patrimonio debe ser una de las herramientas fundamentales a la hora de llevar a la práctica lo que en las agendas aparece de un modo obtuso, frío, académico, políticamente correcto y alejado del lenguaje y el sentir del habitante medio de la ciudad. Lo expuesto en las agendas carece de alma, está alejado del caos, el ruido, la vitalidad de la vida urbana y del fluir de sus habitantes.

Para afrontar el desarrollo urbano del futuro es necesario primero imaginar qué tipo de ciudad se quiere para el mismo. Al fin y al cabo vivimos en un mundo donde la imagen prima, también en el ámbito urbano (BRANDAO, 2011). Es necesario previsualizar, diseñar, generar bocetos de aquello que se quiere modificar. Es éste un paso fundamental que a día de hoy no puede ser hecho desde lo alto de ninguna jerarquía. No son los políticos ni los urbanistas los responsables de las nuevas visiones y trazados de la ciudad, sino sus propios ciudadanos.

Las instituciones, asociaciones culturales, las industrias creativas y sus propios usuarios, bien de un modo colectivo o individual, son los que deben adquirir la responsabilidad de dar a conocer su(s) visión(es) urbanas. La nueva era digital permite con facilidad que los habitantes de la ciudad puedan generar contenido sobre sus vivencias en la misma. Estos contenidos pueden adquirir muy diversos tipos (fotografías, vídeos, comentarios, acciones...) que pueden ser compartidos en páginas webs, blogs, redes sociales... Después de todo conformando narrativas más o menos simples o complejas, relatos que informan del verdadero acontecer diario en la ciudad.

Las perspectivas sobre la ciudad están siendo producidas por sus ciudadanos, aunque probablemente no adquieren la dimensión necesaria para ser tenidas en cuentas por las autoridades. No son ampliamente conocidas ni distribuidas. Al menos hasta el momento.
Por ello, en el desarrollo urbano futuro no parece necesaria la generación de grandes proyectos que rediseñen los espacios y agrupen las identidades desde las instancias políticas. Ya no se requieren campañas de marketing o city branding, tampoco megalómanas escenografías o monumentos, claramente insostenibles. Lo que sí debe pasar es que esas instancias políticas permanezcan abiertas a escuchar la voz de todos los grupos sociales, de la diversidad de comunidades e individuos que conforman la ciudad. Ese paso es crucial para que la ciudadanía establezca una primera toma de contacto de su propia responsabilidad, de su papel activo en el futuro del espacio que habitan.

Serán pues los propios ciudadanos los que alzando la voz, utilizando las redes de comunicación ya existentes o creando nuevas, tengan que dar el salto de ser habitantes pasivos a convertirse en sujetos activos en la conformación de la ciudad, en un sentido tangible e intangible: apropiándose del uso de los espacios públicos tanto como de sus símbolos e iconos, o bien creando y conformando nuevas imágenes e imaginarios de la ciudad.

Esta participación será posible gracias al uso de las plataformas colectivas que el patrimonio ofrece a la comunidad: los espacios físicos de intercambio de experiencias y conocimiento, desde las plazas de los centros históricos o los museos; hasta, desde un punto de vista inmaterial, la memoria e identidad compartida. Las experiencias y relatos generados de este modo permitirán la inclusión de la diversidad en contraposición a la monolítica tradición y unidimensionalidad de la Historia con mayúsculas.

El conocido como storytelling, la narración de la ciudad, se establece así como un factor clave de democratización y sostenibilidad (BEAUREGARD, 2003). En sí misma, esta(s) narrativa(s) se presenta(n) como elemento patrimonial: el relato no deja de ser una técnica, un mecanismo cultural al servicio del ser humano desde sus propios orígenes. Una máquina de inspiración creativa de mayor o menor calado en forma de arte, literatura, música... 
a debate El papel del patrimonio en las nuevas políticas para la cultura, la ciudad y el territorio: las agendas urbanas como marco de oportunidad

| coordinan Blanca del Espino Hidalgo, Rafael Merinero Rodríguez

La ciudad es un palimpsesto (HUYSSEN, 2003). Un texto abierto donde siempre se adivinarán las huellas del pasado, el patrimonio, aquello que perdura en el tiempo. La narración urbana debe estar pues abierta al futuro como prioridad sin caer en la amnesia. Los relatos de la ciudad se basan en la memoria, de lo recordado o de aquello que se quiere recordar. La ciudad debe ser escuchada y reescrita de un modo inclusivo. Esa narración tendrá necesariamente que ser asumida por los propios actores y relatores de la ciudad, sus ciudadanos. El futuro de la ciudad y del patrimonio permanece abiertos. Su guión está por escribir.

\section{BIBLIOGRAFÍA}

- BEAUREGARD, R. (2003) Democracy, storytelling, and the sustainable city. En ECKSTE, B.; THROGMORTON,J. (ed.) Story and sustainability. Plannig, practise, and possibility for American cities. Cambridge, MA: MIT Press, 2003, pp. 65-77

- BRANDÃO, P. (2011) La imagen de la ciudad: estrategias de identidad y comunicación. Barcelona: U. Barcelona, 2011

- BURGESS, J. (2006) Hearing ordinary voices: Cultural studies, vernacular creativity and digital storytelling. Continuum, 20 (2), 2006, pp. 201-214

- CULTURE: Urban Future. Global Report on Culture for Sustainable Urban Development (2016) UNESCO

- FINNEGAN, R. (1998) Tales of the City. A Study of Narrative and Urban Life. Cambridge: Cambridge University Press, 1998

- GIACCARDI, E. (ed.) (2012) Heritage and social media: Understanding heritage in a participatory culture. London: Routledge, 2012

- HUYSSEN, A. (2003) Present pasts: Urban palimpsests and the politics of memory. Stanford, Calif.: Stanford University Press, 2003

- JENSEN, O. B. (2007) Culture stories: Understanding cultural urban branding. Planning Theory, 6(3), 2007, pp. 211236

- LAMBERT, J. (2013) Digital storytelling: Capturing lives, creating community. London: Routledge, 2013

- MALPAS, J. (2008) New media, cultural heritage and the sense of place: Mapping the conceptual ground. International Journal of Heritage Studies, vol. 14, n. ${ }^{0} 3$, 2008, pp. 197-209

- NAS, P. J. (2016) Cities full of symbols: a theory of urban space and culture. Leiden: Leiden University Press, 2016

- NAS, P.; SAMUELS, A. (ed.) (2006) Hypercity: the symbolic side of urbanism. London, Bahrain, New York: Kegan Paul, 2006

- RIDGE, M. M. (ed.) (2014) Crowdsourcing our cultural heritage. Farnham: Ashgate Publishing, Ltd., 2014

- RIENIETS, T.; SIGLER, J.; CHRISTIAANSE, K. (2009) Open city: Designing coexistence. Amsterdam: SUN, 2009

- SASSEN, S. (2016) Global networks, linked cities. London: Routledge, 2016

- THROGMORTON, J. A. (2003) Planning as persuasive storytelling in a global-scale web of relationships. Planning Theory, 2(2), 2003, pp. 125-151

- WATERTON, E. (2009) Sights of sites: picturing heritage, power and exclusion. Journal of Heritage Tourism, 4(1), 2009, pp. 37-56 